\title{
Sugar-sweetened soft drinks are associated with poorer cognitive function in individuals with type 2 diabetes: the Maine-Syracuse Longitudinal Study
}

\author{
Georgina E. Crichton ${ }^{1 *}$, Merrill F. Elias ${ }^{2,3}$ and Rachael V. Torres ${ }^{2}$ \\ ${ }^{1}$ Nutritional Physiology Research Centre, University of South Australia, Adelaide, SA 50011, Australia \\ ${ }^{2}$ Department of Psychology, University of Maine, Orono, ME 04469, USA \\ ${ }^{3}$ Graduate School of Biomedical Sciences and Engineering, University of Maine, Orono, ME O4469, USA \\ (Submitted 22 July 2015 - Final revision received 20 December 2015 - Accepted 17 January 2016)
}

\section{Abstract}

The importance of adequate nutrition on cognitive performance is well recognised. Greater intakes of soft drinks are associated with a higher risk for type 2 diabetes, as well as other cardiometabolic diseases. A few studies have specifically examined whether the intake of soft drinks may be related to cognitive function. The aim of this study was to investigate whether soft drink intakes, including both sugar-sweetened and diet beverages, are associated with cognitive function, with adjustment for cardiovascular, lifestyle and dietary factors, and stratified according to type 2 diabetes status. Cross-sectional analyses were undertaken using 803 community-dwelling participants, aged 23-98 years, from the Maine-Syracuse Longitudinal Study. Cognitive function was measured using an extensive battery of neuropsychological tests. Usual dietary intake of soft drinks was assessed using a FFQ. Stratification by type 2 diabetes indicated that a greater intake of sugar-sweetened soft drinks was significantly associated with poorer performance in visual spatial memory, working memory, scanning and tracking, executive function, the global composite and the Mini-Mental State Examination in diabetic individuals. These relations were not attenuated with statistical control for BMI and other cardiovascular, lifestyle and dietary factors. Diet soft drink intake was unrelated to cognitive performance. Frequent sugar-sweetened soft drink intake was associated with poorer cognitive performance, particularly in individuals with type 2 diabetes, but the underlying causal mechanisms are yet to be determined. Longitudinal studies are needed to clarify these findings and the underlying causal mechanisms.

\section{Key words: Cognitive function: Sugar-sweetened beverages: Soft drinks: Type 2 diabetes}

Consumption of sugar-sweetened beverages (SSB) has more than doubled in the USA in the past 50 years $^{(1)}$, providing a significant source of energy to the diet of Americans. Sugary drinks make up about $9 \%$ of the US daily energy intake ${ }^{(2)}$ and $>40 \%$ of 'added sugars' in the diet ${ }^{(3)}$. Sucrose and high-fructose maize syrup are sugars commonly used to sweeten soft drinks, whereas artificial sweeteners such as aspartame are used in diet soft drinks.

Data from cross-sectional, longitudinal and experimental studies implicate a high intake of sweetened beverages and risk for cardiometabolic risk factors and diseases including obesity $^{(4,5)}$, type 2 diabetes mellitus ${ }^{(6-8)}$, hypertension ${ }^{(9)}$ and the metabolic syndrome ${ }^{(7,10)}$. Obesity rates have also risen over the same period of time that intakes of sugar-containing beverages have increased ${ }^{(1)}$, with more than two-thirds of American adults $(68.8 \%)$ currently classified as overweight or obese $^{(11)}$. The prevalence of type 2 diabetes in the USA is also increasing, affecting over 29 million Americans (9.3\% of the population in 2012) ${ }^{(12)}$. These risk factors have all been linked with impaired cognitive functioning ${ }^{(13,14)}$. Decrements in cognition and memory complaints in healthy individuals represent an increased risk for the development of dementia later in life ${ }^{(15,16)}$.

Although numerous studies have examined the association between soft drinks (both sugar-sweetened and artificially sweetened) and cardiometabolic outcomes, fewer studies have specifically assessed soft drink intake, including both regular and diet drinks, in relation to cognition. In one recent study, greater intakes of total sugars, added sugars and SSB (including both carbonated and fruit drinks with added sugars) were associated with poorer performance on a general global cognition measure, the Mini-Mental State Examination (MMSE), in middle aged to elderly adults free of diabetes ${ }^{(17)}$.

In the present study, we examined the relationships between soft drink intake and cognitive function in a community-based, dementia-free population. We distinguished soft drinks from SSB, which included fruit drinks with added sugars, included individuals with diabetes in the analysis and utilised a thorough

Abbreviations: AD, Alzheimer's disease; MMSE, Mini-Mental State Examination; MSLS, Maine-Syracuse Longitudinal Study; SSB, sugar-sweetened beverages. 
cognitive test battery comprised of multiple cognitive domains. As it remains unclear whether sugar-sweetened soft drinks differ in their relations with cognition relative to diet soft drinks, we also examined these relationships, before and after adjustment for cardiovascular risk factors and dietary and lifestyle factors that impact upon cognition. Finally, due to the significant amount of research linking type 2 diabetes with intakes of SSB and with cognitive performance, we examined whether relations vary according to diabetes status.

\section{Methods \\ Participants}

Participants were selected from the Maine-Syracuse Longitudinal Study (MSLS), a community-based study of cardiovascular risk factors and cognitive functioning in adults ${ }^{(18-21)}$. The MSLS consists of five cohorts defined by time of entry into the study (1975-2000). At initial recruitment, participants were living independently in Syracuse, New York. The only exclusions at recruitment were diagnosis of or treatment for psychiatric illness, alcoholism and inability to comprehend English. Participants of the present study were those returning for the sixth study wave (2001-2006), as dietary intake measures were first obtained at this time. The MSLS was approved by the University of Maine Institutional Review Board, and informed consent for data collection and medical record review was obtained from all participants.

From a sample of 1049 individuals, participants were excluded for the following reasons: missing dietary or cognitive data ( $n$ 169), acute stroke ( $n$ 28), probable dementia ( $n$ 8), undertaking dialysis treatment ( $n$ 5), inability to read English $(n 1)$ and previous alcohol abuse ( $n$ 1), leaving 803 participants. Dementia cases were excluded as we were interested in examining relationships between diet and cognitive performance, but not in those with severe cognitive impairment. The clinical diagnosis of dementia was determined by the committee using the National Institute of Neurological and Communicative Diseases and Stroke/Alzheimer's Disease and Related Disorders Association criteria, MSLS cognition data, diagnostic records and medical interview data ${ }^{(22)}$. Stroke was defined as a focal neurological deficit of acute onset persisting for more than $24 \mathrm{~h}$ and was based on self-report or medical records.

This study was conducted according to the guidelines laid down in the Declaration of Helsinki, and all procedures were approved by the University of Maine Institutional Review Board. Written informed consent was obtained from all subjects.

\section{Procedure and assessment}

Demographic, socio-economic and lifestyle characteristics were obtained from the Nutrition and Health Questionnaire ${ }^{(23,24)}$. Data obtained included smoking history, living situation, marital status and medical history. Physical activity was measured using the Nurses' Health Study Activity Questionnaire - a validated measure of time spent engaging in various physical activities ${ }^{(25)}$. The Center for Epidemiological Studies Depression Scale ${ }^{(26)}$ was used to assess depressive symptoms. Education level was obtained through self-report and ranged from 4 to 20 years.

\section{Dietary intake}

Dietary intake was also assessed using the Nutrition and Health Questionnaire ${ }^{(23,24)}$. Participants were required to stipulate how frequently they consumed a list of foods including meat, fish, eggs, breads, cereals, rice and pasta, fruits, vegetables, dairy foods, chocolate, nuts, other snack-type foods and beverages. Participants were required to stipulate how frequently they consumed each food item, with six response options ranging from never to once or more per day. Beverages included tea, coffee, water, fruit juice and alcohol. For soft drinks, participants were required to indicate how many glasses/cans of carbonated soft drinks (regular, sugar-sweetened) and 'diet' carbonated soft drinks (artificially sweetened) they consumed each day.

In order to estimate the mean intakes of the major food groups and total energy intake, the median score within each response option was used to estimate total intakes per week for example, two to three times per week was estimated at $2 \cdot 5$. The mean number of times each food was consumed on a weekly and then daily basis was calculated for all foods in the questionnaire. As portion sizes were not stipulated to participants, these totals are an estimate of the number of times each food was consumed on a daily basis. Individual foods were categorised into six major food groups - grains, fruits, vegetables, protein foods, dairy foods and fats/sweets/other - based on the United States Department of Agriculture Food Guide Pyramid $^{(27)}$. Intakes of individual foods and beverages within each food group were summed to give an estimate of total intake for each group. An estimation of total energy intake was calculated by adding intakes of all food groups and was used to control for energy intake in subsequent analyses.

\section{Cognitive function}

Cognitive function was assessed using the MSLS neuropsychological test battery, which has been used in numerous health and cognition studies ${ }^{(18-21,28)}$. The following composite scores have been previously derived using factor analysis from twenty individual tests designed to measure a wide range of cognitive domains: visual spatial memory and Organisation, scanning and tracking, Verbal Episodic Memory, working memory and executive function. The Wechsler Adult Intelligence Scale (WAIS) similarities test ${ }^{(29)}$, a measure of abstract reasoning, loaded on all composite scores (factors), and was thus used separately. A global cognition composite score was derived by averaging the $z$-scores for all individual tests and then re-standardising these scores to obtain a $z$-score with a mean of 0 and SD of 1.00. In addition, the $\mathrm{MMSE}^{(30)}$, a global measure of mental status widely used in the literature, was included in the MSLS battery. The derivation of these composites has been described previously ${ }^{(20)}$ and they have been repeatedly utilised in MSLS studies. All cognitive performance measures are expressed in the same unit of measurement (sD units) - that is, $z$-scores. 


\section{Physical health assessment}

Standardised protocols for data collection were used. Standard assay methods were used ${ }^{(20)}$ to obtain values of fasting plasma glucose $(\mathrm{mmol} / \mathrm{l})$, total cholesterol (TC, mmol/l), LDL-cholesterol (mmol/l), HDL-cholesterol $(\mathrm{mmol} / \mathrm{l})$, TAG $(\mathrm{mmol} / \mathrm{l})$ and C-reactive protein (CRP, nmol/l), following an overnight fast. Body weight was measured with participants wearing light clothing to the nearest $0 \cdot 1 \mathrm{~kg}$, and height was measured using a vertical ruler to the nearest $0 \cdot 1 \mathrm{~cm}$. BMI was calculated as weight in kilograms divided by height in metres squared. Waist circumference (cm) was measured over light clothing, using a non-extendable measuring tape, at the level of the iliac crest. Automated blood pressure (BP) measures (GE DINAMAP 100DPC-120XEN; GE Healthcare) were taken five times each in the reclining, sitting and standing positions after a supine rest for $15 \mathrm{~min}$, and were averaged for systolic and diastolic BP. Obesity was defined as having a BMI of at least $30 \mathrm{~kg} / \mathrm{m}^{2}$.

\section{Interaction with diabetes}

Diabetes was defined as having a fasting glucose level of at least $7.0 \mathrm{mmol} / \mathrm{l}$ or being treated with anti-diabetic medication. Any interaction between diabetes status and soft drink intake was tested. Two interaction terms were created: diabetes $(\mathrm{Y} / \mathrm{N}) \times$ regular soft drink intake and diabetes $(\mathrm{Y} / \mathrm{N}) \times \operatorname{diet}$ soft drink intake. These terms were included in the basic model (described below) to test for such interactions.

\section{Statistical analyses}

Participant demographics, health and dietary variables and cognitive scores were compared according to soft drink intake (type and quantity). Independent samples $t$ tests were used for continuous variables and $\chi^{2}$ test for categorical variables.

Regular and diet soft drink intakes were examined in relation to each measure of cognitive performance using multiple linear regression. Potential confounding factors were identified on the basis of two criteria: (1) had to be theoretically relevant ${ }^{(31)}$ and (2) had to show a statistically significant association $(P<0.05)$ with both soft drink intake and the global composite.

The covariates included were organised into three models:

(1) Basic set: age, sex and education.

(2) Extended covariate set 1: basic set plus estimated energy intake (total daily intakes of all food groups as previously described), depressed mood, CRP, HDL-cholesterol, TAG, diabetes and total grains, fruit and vegetable intakes per day.

(3) Extended covariate set 2: the basic set and extended set 1 plus BMI.

The other risk factors measured did not correlate significantly with both predictor and outcome, and thus were not included in the statistical models. As a significant interaction between diabetes and regular soft drink intake was observed, these analyses were performed according to diabetes status $(\mathrm{Y} / \mathrm{N})$.

All the statistical analyses were performed using PASW for Windows ${ }^{\circledR}$ version 21.0 software (formerly SPSS Statistics Inc.); $P<0.05$ was considered to be statistically significant.
Results

\section{Participant characteristics and soft drink consumption}

Table 1 shows the demographic and health-related variables, cognitive scores and dietary intakes of the MSLS participants, according to soft drink intake. Nearly $20 \%$ of the sample consumed one or more regular soft drinks each day, and $27 \%$ consumed at least one diet soft drink per day. Males consumed regular soft drinks more frequently than females. Individuals who did not consume regular soft drinks smoked less, had lower waist circumference and BMI, lower TAG and higher HDL-cholesterol, compared with those who consumed regular soft drinks daily. They also had significantly higher scores on a number of cognitive performance measures. From a dietary perspective, non-consumers of regular soft drinks had higher intakes of fruit and vegetables and lower intakes of grains and overall energy. Individuals who did not consume diet soft drinks had lower cognitive scores than those who consumed diet soft drinks daily.

The online Supplementary Table S1 shows the demographic and health-related variables, cognitive scores and dietary intakes of the MSLS participants, according to diabetes status $(\mathrm{Y} / \mathrm{N})$.

Soft drink consumption and cognitive performance in the Maine-Syracuse Longitudinal Study: stratification by diabetes

A significant interaction was observed between diabetes status and daily regular soft drink intake (basic model: $b=-0 \cdot 30$, $P=0.009)$. No interaction was observed for diet soft drinks and diabetes $(b=0.09, P=0.09)$. Table 2 summarises the associations between regular soda intake and cognitive functioning measures, stratified by the presence or absence of diabetes.

In individuals with type 2 diabetes, there were significant linear, inverse associations between regular soft drink intake and cognitive functioning scores for the global composite, visual spatial memory and organisation, working memory, scanning and tracking, executive function and MMSE (all $P<0 \cdot 01$, basic model). With the addition of cardiovascular, lifestyle and dietary risk factors, significant inverse linear associations remained for all of these cognitive outcomes. The addition of BMI to this model did not attenuate these associations (all $P<0.05$ ).

In non-diabetic individuals, there were significant linear, inverse associations between regular soft drink intake and cognitive functioning scores for the global composite, working memory, scanning and tracking, executive function and MMSE (all $P<0 \cdot 01$, basic model). All these relationships remained significant with further statistical adjustment for cardiovascular, lifestyle, dietary factors and BMI (extended 2 model, all $P<0.05)$.

Fig. 1 and 2 show the multivariate adjusted $z$-scores for the global composite and the MMSE, respectively, in diabetic and nondiabetic individuals. As can be seen, scores decreased significantly for both measures, in both subject groups, as regular soft drink intakes increased; however, the differences between scores were considerably greater in those with type 2 diabetes. 
Table 1. Baseline demographics and health and dietary factors according to soft drink intake in the Maine-Syracuse Longitudinal Study sample ( $n$ 803) (Mean values and standard deviations)

\begin{tabular}{|c|c|c|c|c|c|c|c|c|}
\hline \multirow[b]{4}{*}{ Characteristics } & \multicolumn{8}{|c|}{ Soft drink intake } \\
\hline & \multicolumn{4}{|c|}{ Regular soft drink } & \multicolumn{4}{|c|}{ Diet soft drink } \\
\hline & \multicolumn{2}{|c|}{ 0/d $(n 651(81.1 \%))$} & \multicolumn{2}{|c|}{$\geq 1 / \mathrm{d}(n 152(18.9 \%))$} & \multicolumn{2}{|c|}{ 0/d $(n 590(73.5 \%))$} & \multicolumn{2}{|c|}{$\geq 1 / \mathrm{d}(n 213(26.5 \%))$} \\
\hline & Mean & SD & Mean & SD & Mean & SD & Mean & SD \\
\hline Age (years) & $63 \cdot 0^{\star \star *}$ & $12 \cdot 6$ & 56.5 & $12 \cdot 7$ & $62 \cdot 6^{\star \star}$ & $13 \cdot 3$ & 59.6 & 11.6 \\
\hline Sex (\% male) & $36 \cdot 5^{\star \star \star}$ & & $56 \cdot 3$ & & $40 \cdot 7$ & & 38.5 & \\
\hline Education (years) & $14 \cdot 8^{\star \star}$ & $2 \cdot 7$ & $14 \cdot 1$ & $2 \cdot 8$ & 14.6 & $2 \cdot 7$ & 14.9 & $2 \cdot 7$ \\
\hline Physical activity (min/d) & 37 & 47 & 38 & 55 & 36 & 49 & 39 & 48 \\
\hline Smoking status (cigarettes/d) & $0.9^{\star * *}$ & 4.4 & 3.4 & 8.0 & 1.4 & $5 \cdot 3$ & $1 \cdot 1$ & $5 \cdot 4$ \\
\hline Systolic BP (mmHg) & 131 & 22 & 132 & 23 & 131 & 22 & 131 & 23 \\
\hline Diastolic BP $(\mathrm{mmHg})$ & 70 & 10 & 71 & 10 & 70 & 10 & 71 & 9.6 \\
\hline Waist circumference (cm) & $93^{\star \star *}$ & 15 & 102 & 17 & 94 & 15 & 97 & 15 \\
\hline Total cholesterol (mmol/l) & $5 \cdot 2$ & 1.0 & $5 \cdot 3$ & $1 \cdot 1$ & 5.3 & 1.0 & $5 \cdot 1$ & $1 \cdot 1$ \\
\hline HDL-cholesterol (mmol/l) & $1.5^{\star \star \star}$ & 0.4 & 1.2 & 0.3 & 1.4 & 0.4 & 1.4 & 0.4 \\
\hline LDL-cholesterol (mmol/l) & 3.3 & 0.9 & $3 \cdot 2$ & 1.0 & 3.2 & 0.9 & 0.5 & 0.9 \\
\hline Fasting plasma glucose $(\mathrm{mmol} / \mathrm{l})$ & $5 \cdot 4$ & 1.6 & 5.6 & 1.4 & $5 \cdot 4$ & 1.4 & $5 \cdot 6$ & 1.7 \\
\hline $\mathrm{TAG}(\mathrm{mmol} / \mathrm{l})$ & $1 \cdot 5^{\star \star \star}$ & 1.0 & $2 \cdot 0$ & 1.9 & 1.6 & 1.3 & 1.6 & $1 \cdot 1$ \\
\hline C-reactive protein $(\mathrm{nmol} / \mathrm{l})$ & $3 \cdot 8^{*}$ & 4.1 & 4.8 & $5 \cdot 7$ & 4.0 & 4.6 & 4.1 & 4.3 \\
\hline BMI $\left(\mathrm{kg} / \mathrm{m}^{2}\right)$ & $28 \cdot 7^{\star * *}$ & 5.5 & 31.6 & $7 \cdot 7$ & $28 \cdot 9^{\star \star}$ & $6 \cdot 0$ & $30 \cdot 3$ & $6 \cdot 1$ \\
\hline Depressed mood, CES-D score $†$ & $7 \cdot 3$ & 6.9 & 8.4 & $6 \cdot 7$ & $7 \cdot 7$ & $7 \cdot 1$ & $7 \cdot 2$ & 6.4 \\
\hline Diabetes (\%)‡ & 11.4 & & $13 \cdot 9$ & & $10 \cdot 5^{\star}$ & & $16 \cdot 0$ & \\
\hline Hypertension (\%) & 60.5 & & $63 \cdot 6$ & & 61.0 & & 61.5 & \\
\hline Obesity (\%) & $35 \cdot 0^{\star \star}$ & & $49 \cdot 7$ & & $34 \cdot 7^{\star \star}$ & & $46 \cdot 4$ & \\
\hline \multicolumn{9}{|l|}{ Cognitive scores } \\
\hline Global composite & 0.09 & 0.04 & -0.05 & 0.08 & $0.01^{*}$ & 0.04 & 0.22 & 0.07 \\
\hline Visual spatial memory and organisation & 0.06 & 0.04 & 0.08 & 0.08 & 0.03 & 0.04 & 0.15 & 0.07 \\
\hline Scanning and tracking & 0.05 & 0.04 & -0.02 & 0.08 & $-0.03^{\star \star}$ & 0.04 & 0.23 & 0.07 \\
\hline Verbal memory & 0.07 & 0.04 & -0.04 & 0.08 & $-0.01^{\star}$ & 0.04 & 0.22 & 0.07 \\
\hline Working memory & $0 \cdot 11^{\star *}$ & 0.04 & -0.18 & 0.09 & 0.03 & 0.04 & 0.14 & 0.06 \\
\hline Executive function & $0 \cdot 10^{\star \star}$ & 0.04 & -0.16 & 0.08 & $0^{\star \star}$ & 0.04 & 0.21 & 0.07 \\
\hline Similarities & $0 \cdot 11^{\star \star}$ & 0.04 & -0.19 & 0.08 & 0.02 & 0.04 & 0.13 & 0.06 \\
\hline Mini-Mental State Examination & $0.09^{\star *}$ & 0.04 & -0.20 & 0.10 & $-0.01^{*}$ & 0.04 & 0.15 & 0.06 \\
\hline \multicolumn{9}{|l|}{ Dietary variables } \\
\hline Regular soft drinks/d & $0^{\star \star \star}$ & 0 & 1.8 & 1.7 & $0.4^{\star \star}$ & $1 \cdot 1$ & 0.2 & 0.5 \\
\hline Diet soft drinks/d & $0.5^{\star \star}$ & 1.0 & 0.2 & 0.7 & $0^{\star \star \star}$ & 0 & 1.7 & 1.2 \\
\hline Total energy intake§ & $14 \cdot 0^{\star * *}$ & $4 \cdot 1$ & $16 \cdot 5$ & $5 \cdot 4$ & $14 \cdot 7^{\star}$ & 4.6 & $13 \cdot 9$ & 3.9 \\
\hline Vegetables (servings/d) & $2 \cdot 8^{\star \star \star}$ & $1 \cdot 1$ & 2.4 & $1 \cdot 1$ & $2 \cdot 7$ & $1 \cdot 1$ & $2 \cdot 7$ & 1.0 \\
\hline Fruits (servings/d) & $1.6^{*}$ & 1.0 & 1.4 & 1.0 & 1.6 & 1.0 & 1.5 & 0.9 \\
\hline Grains (servings/d) & $3.5^{\star *}$ & 1.9 & $4 \cdot 1$ & $2 \cdot 1$ & 3.6 & $2 \cdot 1$ & 3.5 & 1.8 \\
\hline Meat (servings/d) & $2 \cdot 0$ & 0.9 & $2 \cdot 1$ & 1.0 & $2 \cdot 0$ & 0.9 & $2 \cdot 1$ & 1.0 \\
\hline Dairy foods (servings/d) & $2 \cdot 0$ & 1.0 & 1.9 & 1.2 & $2 \cdot 0$ & 1.1 & 1.9 & 1.0 \\
\hline Alcohol (standard drinks/d) & 0.5 & 1.0 & 0.4 & $1 \cdot 1$ & 0.5 & 1.0 & 0.4 & 0.7 \\
\hline
\end{tabular}

BP, blood pressure; CES-D, Center for Epidemiological Studies Depression Scale.

Mean values are significantly different: ${ }^{*} P<0.05,{ }^{* \star} P<0.01,{ }^{\star \star *} P<0.001$.

$\dagger$ CES-D: higher score indicates greater number of depressive symptoms.

¥ Diabetes defined as having a fasting glucose level of at least $126 \mathrm{mg} / \mathrm{dl}$, or treated with anti-diabetic medication.

$\S$ Total energy intake $=$ total serves/day all food groups.

There were no significant associations found between intakes of diet soft drinks and cognitive outcomes (basic or extended models).

\section{Secondary analyses}

Sensitivity analyses were performed by substituting BMI for waist circumference:waist hip ratio, and the results were unchanged. Any interaction between regular soft drink intake and BMI was tested in relation to the global composite. In both diabetic and non-diabetic individuals, this interaction term was not significant (basic model, diabetic group: $b=-0.004, P=0 \cdot 8$; non-diabetic group: $b=0 \cdot 002, P=0 \cdot 6$ ).
We also tested the same associations between regular and diet soft drink intake and cognitive function in a pre-diabetic subgroup ( $n$ 146). These individuals were defined as having a fasting plasma glucose level of $5 \cdot 5-7 \cdot 0 \mathrm{mmol} / \mathrm{l}^{(32)}$. There were no significant associations between regular or diet soft drink intake and any of the cognitive performance outcomes in this subgroup (basic model, all $P>0 \cdot 08$ ).

\section{Discussion}

Regular, sugar-sweetened soft drink intake was inversely associated with cognitive performance across a range of cognitive domains in this dementia-free, community-dwelling population. The associations between greater regular soft drink 
Table 2. Association between regular soft drink intake (serves/d) and cognitive functioning measures, stratified by diabetes status ${ }^{\star}$ (Raw regression coefficients for $z$-scores with their standard errors)

\begin{tabular}{|c|c|c|c|c|c|c|c|c|c|}
\hline \multirow[b]{2}{*}{ Cognitive outcomes } & \multirow[b]{2}{*}{ Covariate set $\dagger$} & \multicolumn{4}{|c|}{ Diabetic subjects ( $n 96(12 \%))$} & \multicolumn{4}{|c|}{ Non-diabetic subjects $(n 707(88 \%))$} \\
\hline & & $b$ & SE & $B$ & $P$ & $b$ & SE & $B$ & $P$ \\
\hline \multirow[t]{3}{*}{ Global composite } & Basic & -0.45 & 0.14 & -0.29 & 0.001 & -0.08 & 0.03 & -0.09 & 0.003 \\
\hline & Extended 1 & -0.53 & 0.18 & -0.33 & 0.003 & -0.06 & 0.03 & -0.08 & 0.037 \\
\hline & Extended 2 & -0.52 & 0.18 & -0.32 & 0.005 & -0.07 & 0.03 & -0.08 & 0.034 \\
\hline \multirow[t]{3}{*}{ Visual spatial memory and organisation } & Basic & -0.39 & 0.13 & -0.24 & 0.004 & -0.03 & 0.03 & -0.04 & 0.27 \\
\hline & Extended 1 & -0.43 & 0.17 & -0.26 & 0.012 & -0.02 & 0.03 & -0.02 & 0.64 \\
\hline & Extended 2 & -0.43 & 0.17 & -0.26 & 0.016 & -0.02 & 0.03 & -0.02 & 0.61 \\
\hline \multirow[t]{3}{*}{ Verbal memory } & Basic & -0.30 & 0.17 & -0.19 & 0.08 & -0.06 & 0.03 & -0.06 & 0.07 \\
\hline & Extended 1 & -0.22 & 0.22 & -0.13 & 0.33 & -0.05 & 0.04 & -0.05 & 0.22 \\
\hline & Extended 2 & -0.23 & 0.23 & -0.14 & 0.32 & -0.05 & 0.04 & -0.05 & 0.20 \\
\hline \multirow{3}{*}{ Working memory } & Basic & -0.44 & 0.16 & -0.30 & 0.007 & -0.10 & 0.03 & -0.11 & 0.003 \\
\hline & Extended 1 & -0.63 & 0.21 & -0.43 & 0.004 & -0.09 & 0.04 & -0.10 & 0.030 \\
\hline & Extended 2 & -0.66 & 0.21 & -0.45 & 0.003 & -0.09 & 0.04 & $-0 \cdot 10$ & 0.029 \\
\hline \multirow[t]{3}{*}{ Scanning and tracking } & Basic & -0.39 & 0.13 & -0.27 & 0.004 & -0.08 & 0.03 & -0.09 & 0.002 \\
\hline & Extended 1 & -0.40 & 0.17 & -0.27 & 0.018 & -0.08 & 0.03 & -0.09 & 0.012 \\
\hline & Extended 2 & -0.35 & 0.17 & -0.24 & 0.041 & -0.08 & 0.03 & -0.09 & 0.011 \\
\hline \multirow[t]{3}{*}{ Executive function } & Basic & -0.44 & 0.15 & -0.29 & 0.005 & -0.09 & 0.03 & -0.10 & 0.003 \\
\hline & Extended 1 & -0.55 & 0.20 & -0.35 & 0.006 & -0.08 & 0.04 & -0.09 & 0.022 \\
\hline & Extended 2 & -0.53 & 0.20 & -0.34 & 0.011 & -0.09 & 0.04 & -0.10 & 0.020 \\
\hline \multirow[t]{3}{*}{ Similarities } & Basic & -0.12 & 0.16 & -0.07 & 0.46 & -0.06 & 0.03 & -0.07 & 0.07 \\
\hline & Extended 1 & -0.40 & 0.20 & -0.25 & 0.047 & -0.05 & 0.04 & -0.06 & 0.20 \\
\hline & Extended 2 & -0.32 & 0.20 & -0.20 & 0.11 & -0.04 & 0.04 & -0.05 & 0.24 \\
\hline \multirow[t]{3}{*}{ Mini-Mental State Examination } & Basic & -0.52 & 0.19 & -0.29 & 0.007 & $-0 \cdot 10$ & 0.03 & -0.11 & 0.002 \\
\hline & Extended 1 & -0.57 & 0.24 & -0.31 & 0.018 & -0.08 & 0.04 & -0.10 & 0.021 \\
\hline & Extended 2 & -0.54 & 0.24 & -0.29 & 0.028 & -0.08 & 0.04 & -0.10 & 0.020 \\
\hline
\end{tabular}

* Diabetes defined as having a fasting glucose level of at least $126 \mathrm{mg} / \mathrm{dl}$, or treated with anti-diabetic medication.

† Basic model: regression coefficients were adjusted age, education, sex; extended model 1; regression coefficients were adjusted for variables in basic model plus age, education, sex, CES-D, CRP, HDL-cholesterol, TAG, smoking status, total energy intake, total grains per day, total fruits per day, total vegetables per day; extended model 2: regression coefficients were adjusted for variables in basic model and extended model 1 plus BMI.

consumption and poorer cognitive performance remained significant after adjustment for a number of cardiovascular risk factors, including TAG, HDL-cholesterol, CRP and smoking status. Associations were not attenuated with the addition of dietary variables, indicating that soft drinks are associated with cognition, irrespective of other dietary behaviours. In a final step, the addition of BMI did not attenuate these associations. The same result was obtained when the waist circumference:waist hip ratio was substituted for BMI in the sensitivity analyses. These inverse associations were observed for those with and without type 2 diabetes, but the strength of the associations and the magnitude of change across cognitive scores were considerably greater in individuals with diabetes. There were no associations observed between diet soft drink intakes and cognitive performance.

Our results support those of Ye et al. ${ }^{(17)}$, who examined habitual sugar intake and cognitive function in a middle-aged, Puerto Rican sample, excluding diabetic subjects. Ye et al. ${ }^{(17)}$ found that SSB intake, which included fruit drinks as well as soft drinks, was inversely associated with cognitive function. In the Ye et al. ${ }^{(17)}$ study, total sugars, added sugars, sucrose, glucose and added fructose were each significantly, inversely associated with general cognitive function, as measured by the MMSE. No associations between SSB and specific cognitive functions (memory, executive function, attention) were noted. This differs from our study, in which sugar-sweetened soft drinks were inversely associated with a number of specific cognitive domains including visual spatial memory, working memory, scanning and tracking and executive function.

In addition, the present study indicates that inverse associations between soft drinks and cognitive performance are exacerbated in type 2 diabetes patients, and supports the existing literature demonstrating the positive association between intake of sugar-sweetened soft drinks and risk for type 2 diabetes $^{(6-8)}$. A meta-analysis by Malik et al. ${ }^{(7)}$ showed that individuals in the highest quartile of SSB intake (1-2 servings/d) had a $26 \%$ greater risk of developing type 2 diabetes than those in the lowest quartile (none or $<1$ serving/ month). Findings from the Nurses' Health Study II showed that women consuming one or more sugar-sweetened soft drinks per day had a relative risk of 1.83 for developing type 2 diabetes, compared with those who consumed $<1$ serving/month ${ }^{(33)}$. This study included over 91000 women over an 8-year period.

The review by Malik et al. ${ }^{(7)}$ has been supported and expanded upon by a more recent systematic review and metaanalysis by Greenwood et $a l^{(6)}$. These investigators concluded that findings from nine cohort studies indicated a positive association between sugar-sweetened soft drinks and type 2 diabetes risk ${ }^{(6)}$. Exploring dose-response trends, Greenwood et al. ${ }^{(6)}$ have shown that an increase of $330 \mathrm{ml} / \mathrm{d}$ was associated with an approximate increased diabetes risk of $20 \%$. This association was attenuated by adjustment for BMI. For artificially sweetened soft drinks, the trend was less consistent. On the basis of these observations, the authors proposed that 


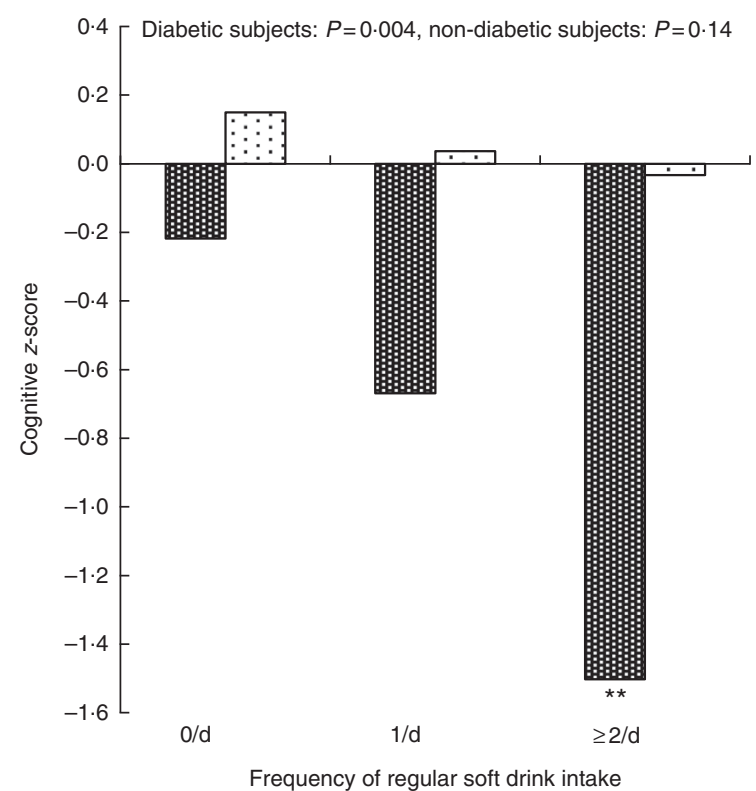

Fig. 1. Multivariate adjusted global composite $z$-scores in diabetic (霞) and non-diabetic (5) subjects according to regular soft drink intake. Z-scores adjusted for age, education, sex, Center for Epidemiological Studies Depression Scale, C-reactive protein, HDL-cholesterol, TAG, smoking, total energy intake, total grains per day, total fruit per day, total vegetables per day, BMI. Significantly different from 0/d group: ${ }^{\star *} P<0.01$.

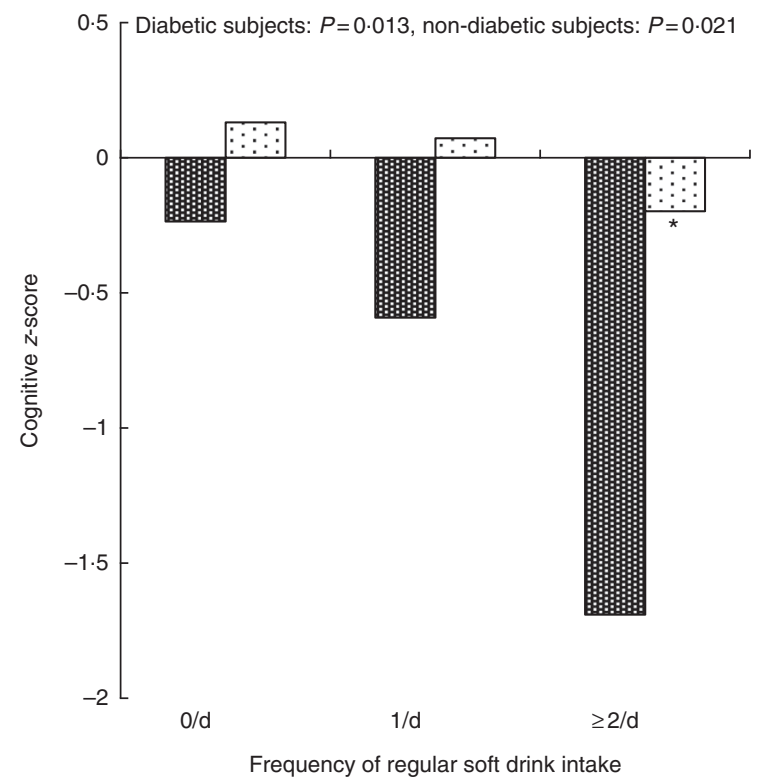

Fig. 2. Multivariate adjusted Mini-Mental State Examination (MMSE) $z$-scores

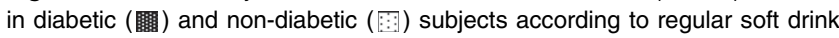
intake. Z-scores adjusted for age, education, sex, Center for Epidemiological Studies Depression Scale, C-reactive protein, HDL-cholesterol, TAG, smoking, total energy intake, total grains per day, total fruit per day, total vegetables per day, BMI. Significantly different from 0/d group: ${ }^{*} P<0.05$.

BMI is involved in the causal pathway between soft drink consumption and type 2 diabetes.

It may therefore be hypothesised that BMI may play a similarly important role in the causal pathway between soft drink consumption and cognitive functioning. In the USA, soft drinks have been the single largest contributor to energy intake during the last decade ${ }^{(34)}$. Mean daily intakes are estimated at $500 \mathrm{ml}$ of soft drinks (or approximately one 16-oz beverage) per person ${ }^{(1,2)}$, with many consuming more than this amount. A typical 20-ounce $(590 \mathrm{ml})$ soda contains 15-18 teaspoons of sugar and upwards of $1.004 \mathrm{~kJ}(0.240 \mathrm{kcal})^{(35)}$. Sugar consumption from a high intake of soft drinks may lead to increased body weight and obesity, which may increase one's risk for type 2 diabetes $^{(10,36)}$, and therefore risk for cognitive decline. This may in part occur as energy from beverages does not appear to produce a resultant decrease in energy obtained from solid food, whereas energy ingested from solid food is followed by an 'off-setting' reduction in the intake of other foods ${ }^{(37)}$. People who consume higher amounts of sugar-containing soft drinks may fail to compensate for these 'calories consumed in liquid form' at their next meal, promoting a positive energy balance and weight gain ${ }^{(38)}$. The energy compensation made for beverages is not equivalent to that made for solid foods, and therefore the energy content of soft drinks can contribute to a cumulative excess of energy over time to produce obesity ${ }^{(36)}$.

Other observational studies and a number of randomised clinical trials have examined associations between sugarcontaining beverages and metabolic outcomes in addition to body composition. Raben et al. ${ }^{(39)}$ compared two groups of overweight individuals consuming either sugar-sweetened cola or aspartame-sweetened cola for 10 weeks. Body weight, fat mass, energy intake and $\mathrm{BP}$ increased in the sucrose group, but these effects were not observed in the artificial sweeteners group.

Stanhope et $a l^{(40)}$ compared the regular intake of glucose $v$. fructose-sweetened beverages in overweight adults for 10 weeks with respect to a number of cardiometabolic outcomes. In subjects consuming the fructose drinks, but not glucose, fasting plasma glucose, insulin and visceral adiposity increased significantly and insulin sensitivity decreased. The fructose may be responsible for visceral fat deposits by providing substrates for fat development when it is metabolised, predominantly in the liver ${ }^{(36)}$. The adverse metabolic effects of fructose have been supported in other studies ${ }^{(41)}$. The fructose in these beverages may stimulate an increase in $\mathrm{TAG}^{(40,41)}$. High-fructose maize syrup is the sole sweetener in US soft drinks ${ }^{(42)}$, and in contrast to glucose fructose does not stimulate insulin secretion or enhance leptin production, both key to the regulation of food intake. High-fructose maize syrup has therefore been suggested as playing a role in the obesity epidemic ${ }^{(42)}$.

A longer-term study lasting 6 months and comparing cardiometabolic effects from the consumption of 1 litre of either sugar-sweetened cola, semi-skimmed milk, aspartamesweetened cola or water showed that the frequent consumption of regular cola resulted in detrimental metabolic changes ${ }^{(43)}$. In the regular soft drink group, visceral, liver and muscle fat, TAG, TC and systolic BP were all significantly increased at the end of the 6-month trial, and these effects were not observed in the remaining groups. The effects of regular cola consumption therefore are not limited to obesity and weight gain, as body weight did not change significantly in this trial. 
A systematic review and meta-analysis by Vartanian et al. ${ }^{(5)}$ examined the association between soft drink consumption and nutrition and health outcomes. Clear associations were found between soft drink intake and increased energy intake, body weight and lower intakes of milk, Ca and other nutrients. This raises the possibility that soft drinks displace other nutrient sources, which may have beneficial effects on not only cardiometabolic health but also brain function. Second, soft drinks may be associated with a higher energy consumption that can be accounted for by the soft drinks alone, which may increase the likelihood that soft drinks ${ }^{(37,38)}$ increase hunger or preference for energy-dense or sweet foods. Relationships have been shown between higher intakes of sugar-sweetened soft drinks and lower intakes of fruit and dietary fibre and higher carbohydrate intakes ${ }^{(5)}$; therefore, soft drink intakes could be an indicator of overall poor dietary habits.

A few studies have suggested that patients with Alzheimer's disease (AD) may have a greater preference for sweet foods than non-impaired controls ${ }^{(44)}$. However, some studies have shown associations between SSB and lower cognitive function, but not sugar-sweetened solid foods ${ }^{(17)}$. This could potentially be due to the differential contributions of sucrose, glucose and fructose in beverages compared with solid foods. It also indicates that the inverse associations between sugar consumption and cognitive function are not explained by other aspects of a poorer dietary pattern - that is, solid foods high in sugar.

Overall, the evidence from clinical studies for the adverse effects from regular consumption of sugar-sweetened soft drinks on risk factors for cardiometabolic disease including obesity, type 2 diabetes, the metabolic syndrome and $\operatorname{CVD}^{(4,5,7,10,36)}$ is substantial. These disease states have all been shown to have a negative impact upon cognition ${ }^{(13,14,45,46)}$. Type 2 diabetes has been repeatedly associated with decreases in psychomotor speed, executive function, verbal and working memory, verbal fluency, recall tasks and global cognitive dysfunction ${ }^{(47-51)}$, as well as risk for dementia and $\mathrm{AD}^{(52-56)}$.

The mechanisms responsible for relative lower cognitive performance in those with type 2 diabetes are not completely understood. Potential mechanisms or causative factors include hyperglycaemia, insulin resistance, hyperinsulinaemia, inflammation and amyloid deposition ${ }^{(51,57)}$. Type 2 diabetes and AD share the common pathophysiology of inflammation ${ }^{(58,59)}$. A high consumption of sugar-sweetened foods and beverages has been demonstrated to increase inflammatory markers ${ }^{(60)}$, which is a major risk factor for diabetes as well as dementia. A second mechanism may be via the disruption of the hypothalamicpituitary-adrenal axis, which occurs with type 2 diabetes, with resultant increased serum cortisol levels ${ }^{(61)}$. Elevated cortisol levels have been associated with deficits in cognitive performance ${ }^{(62)}$. A third mechanism is via the formation of senile plaques composed of $\beta$-amyloid found in $\mathrm{AD}$, as insulin resistance or hyperinsulinaemia may impact upon the metabolism of $\beta$-amyloid, reducing $\beta$-amyloid clearance, and therefore increasing the formation of such plaques ${ }^{(51)}$. Diabetic patients are also more at risk for generalised brain atrophy and greater white matter, high-intensity lesions, indicative of accelerated brain ageing ${ }^{(63,64)}$. Individuals with advanced white matter lesions are at increased risk for executive dysfunction, cognitive decline and dementia ${ }^{(57)}$. The hippocampal and amygdala atrophy seen in subjects with type 2 diabetes with brain imaging are also found to be atrophied in AD patients ${ }^{(65)}$. These areas of the brain are responsible for memory and behaviour. Indeed, cognitive impairment in type 2 diabetes has been more evident for verbal memory than for attention, concentration or executive function ${ }^{(66)}$.

We may hypothesise that the stronger associations between sugar-sweetened soft drinks and cognition in diabetic individuals than in non-diabetic individuals may be due to the combined or accumulative detrimental metabolic effects from both sugar-sweetened soft drinks and type 2 diabetes on the brain. Increased inflammation, for example, is common to both type 2 diabetes and the consumption of sugar-sweetened foods and beverages ${ }^{(51,57,60)}$. This may then be further exacerbated by other poor dietary habits such as increased intakes of energydense or foods high in sugar and lower intakes of fruits and dietary fibre.

Some study limitations must be acknowledged. Our data are cross-sectional, and the dietary questionnaire used has a number of limitations. Soft drink intakes were not specified, regarding the exact serving size. Self-reported nutritional intake can lead to underestimation or overestimation of true associations, and measurement at only one point may not reflect longterm consumption patterns.

The present study has a number of strengths. This is the first cross-sectional study that has examined both regular and diet soft drink intakes and cognitive performance using a standardised battery of cognitive tests while controlling for cardiovascular risk factors and lifestyle and dietary factors. The assessment methods used have enabled us to discriminate between effects on different cognitive domains, and the results may be generalisable to the wider community.

Diet modification is one way in which individuals can potentially prevent or slow neuropsychological dysfunction. In this study, a higher intake of regular soft drinks was associated with poorer cognitive performance, and these relations were particularly strong in those with type 2 diabetes. To enhance our understanding of this possible association, longitudinal studies need to be carried out with detailed assessments of both diet and cognition at multiple time periods. Ultimately, large, well-controlled, long-term intervention trials are needed.

\section{Acknowledgements}

The authors thank Amanda Goodell and Suzanne Brennan, Maine-Syracuse Longitudinal Study, University of Maine, for their help with data acquisition and data management.

The research was supported in part by the National Heart, Lung and Blood Institute (grants HL67358 and HL81290) and the National Institute on Aging (grant AG03055) of the National Institutes of Health to the University of Maine. The first author was supported by a Sidney Sax Research Fellowship (National Health and Medical Research Council, Australia, grant number APP1054567).

The authors' contributions are as follows: M. F. E. contributed to the conception, design and acquisition of data for the MSLS. G. E. C. and M. F. E. conceived the research question. G. E. C. 
analysed the data and drafted the manuscript. R. V. T. contributed to the literature review and interpretation of the data. All the authors contributed to critical revisions, have read and approved the final version of the manuscript.

The authors declare that there are no conflicts of interest.

\section{Supplementary material}

For supplementary material/s referred to in this article, please visit http://dx.doi.org/doi:10.1017/S0007114516000325

\section{References}

1. Popkin BM (2010) Patterns of beverage use across the lifecycle. Physiol Behav 100, 4-9.

2. Nielsen SJ \& Popkin BM (2004) Changes in beverage intake between 1977 and 2001. Am J Prev Med 27, 205-210.

3. Marriott BP, Olsho L, Hadden L, et al. (2010) Intake of added sugars and selected nutrients in the United States, National Health and Nutrition Examination Survey (NHANES) 2003-2006. Crit Rev Food Sci Nutr 50, 228-258.

4. Olsen NJ \& Heitmann BL (2009) Intake of calorically sweetened beverages and obesity. Obes Rev 10, 68-75.

5. Vartanian LR, Schwartz MB \& Brownell KD (2007) Effects of soft drink consumption on nutrition and health: a systematic review and meta-analysis. Am J Public Health 97, 667-675.

6. Greenwood DC, Threapleton DE, Evans CE, et al. (2014) Association between sugar-sweetened and artificially sweetened soft drinks and type 2 diabetes: systematic review and dose-response meta-analysis of prospective studies. Br J Nutr 112, $725-734$.

7. Malik VS, Popkin BM, Bray GA, et al. (2010) Sugar-sweetened beverages and risk of metabolic syndrome and type 2 diabetes. Diabetes Care 33, 2477-2483.

8. O'Connor L, Imamura F, Lentjes MA, et al. (2015) Prospective associations and population impact of sweet beverage intake and type 2 diabetes, and effects of substitutions with alternative beverages. Diabetologia 58, 1474-1483.

9. Chen L, Caballero B, Mitchell DC, et al. (2010) Reducing consumption of sugar-sweetened beverages is associated with reduced blood pressure: a prospective study among United States adults. Circulation 121, 2398-2406.

10. Malik VS, Popkin BM, Bray GA, et al. (2010) Sugar-sweetened beverages, obesity, type 2 diabetes mellitus, and cardiovascular disease risk. Circulation 121, 1356-1364.

11. Flegal KM, Carroll MD, Kit BK, et al. (2012) Prevalence of obesity and trends in the distribution of body mass index among US adults, 1999-2010. JAMA 307, 491-497.

12. American Diabetes Association (2015) Statistics about diabetes. http://www.diabetes.org/diabetes-basics/statistics/ (accessed June 2015).

13. van den Berg E, Dekker JM, Nijpels G, et al. (2008) Cognitive functioning in elderly persons with type 2 diabetes and metabolic syndrome: the Hoorn study. Dement Geriatr Cogn Disord 26, 261-269.

14. van den Berg E, Kloppenborg RP, Kessels RP, et al. (2009) Type 2 diabetes mellitus, hypertension, dyslipidemia and obesity: a systematic comparison of their impact on cognition. Int J Biochem Biophys Mol Biol 1792, 470-481.

15. Elias MF, Beiser A, Wolf PA, et al. (2000) The preclinical phase of Alzheimer disease: a 22-year prospective study of the Framingham Cohort. Arch Neurol 57, 808-813.
16. Jonker C, Geerlings MI \& Schmaud B (2000) Are memory complaints predictive for dementia? A review of clinical and population-based studies. Int J Geriatr Psychiatry 15, 983-991.

17. Ye X, Gao X, Scott T, et al. (2011) Habitual sugar intake and cognitive function among middle-aged and older Puerto Ricans without diabetes. Br J Nutr 106, 1423-1432.

18. Dore GA, Elias MF, Robbins MA, et al. (2008) Relation between central adiposity and cognitive function in the MaineSyracuse Study: attenuation by physical activity. Ann Behav Med 35, 341-350.

19. Elias MF, Robbins MA, Budge MM, et al. (2009) Arterial pulse wave velocity and cognition with advancing age. Hypertension 53, 668-673.

20. Elias MF, Robbins MA, Budge MM, et al. (2006) Homocysteine, folate, and vitamins $\mathrm{B}_{6}$ and $\mathrm{B}_{12}$ blood levels in relation to cognitive performance: the Maine-Syracuse study. Psychosom Med 68, 547-554.

21. Robbins MA, Elias MF, Elias PK, et al. (2005) Blood pressure and cognitive function in an African-American and a Caucasian-American sample: the Maine-Syracuse study. Psychosom Med 67, 707-714.

22. McKhann G, Drachman D, Folstein M, et al. (1984) Clinical diagnosis of Alzheimer's disease: report of the NINCDSADRDA Work Group under the auspices of Department of Health and Human Services Task Force on Alzheimer's Disease. Neurology 34, 939-944.

23. Kaaks R \& Riboli E (1997) Validation and calibration of dietary intake measurements in the EPIC project: methodological considerations. European Prospective Investigation into Cancer and Nutrition. Int J Epidemiol 26, Suppl. 1, S15-S25.

24. Riboli E \& Kaaks R (1997) The EPIC Project: rationale and study design. European Prospective Investigation into Cancer and Nutrition. Int J Epidemiol 26, Suppl. 1, S6-S14.

25. Wolf AM, Hunter DJ, Colditz GA, et al. (1994) Reproducibility and validity of a self-administered physical-activity quesionnaire. Int J Epidemiol 23, 991-999.

26. Radloff LS (1977) The CES-D Scale: a self-report depression scale for research in the general population. Appl Psychol Meas 1, 385-401.

27. United States Department of Agriculture (2011) MyPyramid. gov (accessed April 2011).

28. Elias MF, Elias PK, Seliger SL, et al. (2009) Chronic kidney disease, creatinine and cognitive functioning. Nephrol Dial Transpl 24, 2446-2452.

29. Lezak MD, Howieson DB \& Loring DW (2004) Neuropsychological Assessment, 4th ed.. New York, NY: Oxford University Press.

30. Folstein MF, Folstein SE \& McHugh PR (1975) 'Mini-mental state'. A practical method for grading the cognitive state of patients for the clinician. J Psychiatr Res 12, 189-198.

31. Jaccard J \& Jacoby J (2010) Theory Construction and Modelbuilding Skills: A Practical Guide for Social Scientists. New York, NY: Guilford Press.

32. National Institute of Diabetes and Digestive and Kidney Diseases (2014) Diagnosis of diabetes and prediabetes. www. niddk.nih.gov (accessed December 2015).

33. Schulze MB, Manson JE, Ludwig DS, et al. (2004) Sugarsweetened beverages, weight gain, and incidence of type 2 diabetes in young and middle-aged women. JAMA 292, 927-934.

34. Block G (2004) Foods contributing to energy intake in the US: data from NHANES III and NHANES 1999-2000. I Food Compos Anal 17, 439-447.

35. US Department of Agriculture (2012) Basic report 14400, carbonated beverage, cola, contains caffeine, fast-food cola. National Nutrient Database for Standard Reference, Release 27. Washington, DC: US Department of Agriculture. 
36. Bray GA (2013) Energy and fructose from beverages sweetened with sugar or high-fructose corn syrup pose a health risk for some people. Adv Nutr 4, 220-225.

37. Mattes RD \& Campbell WW (2009) Effects of food form and timing of ingestion on appetite and energy intake in lean young adults and in young adults with obesity. I Am Diet Assoc 109, 430-437.

38. DiMeglio DP \& Mattes RD (2000) Liquid versus solid carbohydrate: effects on food intake and body weight. Int J Obes Relat Metab Disord 24, 794-800.

39. Raben A, Vasilaras TH, Moller AC, et al. (2002) Sucrose compared with artificial sweeteners: different effects on ad libitum food intake and body weight after $10 \mathrm{wk}$ of supplementation in overweight subjects. Am J Clin Nutr 76, 721-729.

40. Stanhope KL, Schwarz JM, Keim NL, et al. (2009) Consuming fructose-sweetened, not glucose-sweetened, beverages increases visceral adiposity and lipids and decreases insulin sensitivity in overweight/obese humans. J Clin Invest 119 , 1322-1334

41. Teff KL, Grudziak J, Townsend RR, et al. (2009) Endocrine and metabolic effects of consuming fructose- and glucosesweetened beverages with meals in obese men and women: influence of insulin resistance on plasma triglyceride responses. J Clin Endocrinol Metab 94, 1562-1569.

42. Bray GA, Nielsen SJ \& Popkin BM (2004) Consumption of high-fructose corn syrup in beverages may play a role in the epidemic of obesity. Am J Clin Nutr 79, 537-543.

43. Maersk M, Belza A, Stodkilde-Jorgensen H, et al. (2012) Sucrose-sweetened beverages increase fat storage in the liver, muscle, and visceral fat depot: a 6-mo randomized intervention study. Am J Clin Nutr 95, 283-289.

44. Mungas D, Cooper JK, Weiler PG, et al. (1990) Dietary preference for sweet foods in patients with dementia. $J \mathrm{Am}$ Geriatr Soc 38, 999-1007.

45. van den Berg E, Biessels GJ, de Craen AJM, et al. (2007) The metabolic syndrome is associated with decelerated cognitive decline in the oldest old. Neurology 69, 979-985.

46. Kivipelto M, Ngandu T, Fratiglioni L, et al. (2005) Obesity and vascular risk factors at midlife and the risk of dementia and Alzheimer disease. Arch Neurol 62, 1556-1560.

47. Gregg EW, Yaffe K, Cauley JA, et al. (2000) Is diabetes associated with cognitive impairment and cognitive decline among older women? Study of Osteoporotic Fractures Research Group. Arch Intern Med 160, 174-180.

48. Yaffe K, Blackwell T, Kanaya AM, et al. (2004) Diabetes, impaired fasting glucose, and development of cognitive impairment in older women. Neurology 63, 658-663.

49. Munshi M, Grande L, Hayes M, et al. (2006) Cognitive dysfunction is associated with poor diabetes control in older adults. Diabetes Care 29, 1794-1799.

50. Messier C (2005) Impact of impaired glucose tolerance and type 2 diabetes on cognitive aging. Neurobiol Aging $\mathbf{2 6}$ Suppl. 1, 26-30.
51. Kodl CT \& Seaquist ER (2008) Cognitive dysfunction and diabetes mellitus. Endocr Rev 29, 494-511.

52. Kloppenborg RP, van den Berg E, Kappelle LJ, et al. (2007) Diabetes and other vascular risk factors for dementia: which factor matters most? A systematic review. Eur J Pharmacol 585, 97-108.

53. Allen KV, Frier BM \& Strachan MW (2004) The relationship between type 2 diabetes and cognitive dysfunction: longitudinal studies and their methodological limitations. Eur $J$ Pharmacol 490, 169-175.

54. Peila R, Rodriguez BL \& Launer LJ (2002) Type 2 diabetes, APOE gene, and the risk for dementia and related pathologies: the Honolulu-Asia Aging Study. Diabetes 51, 1256-1262.

55. Ott A, Stolk RP, van Harskamp F, et al. (1999) Diabetes mellitus and the risk of dementia: the Rotterdam Study. Neurology $\mathbf{5 3}$, 1937-1942.

56. Biessels GJ, Staekenborg S, Brunner E, et al. (2006) Risk of dementia in diabetes mellitus: a systematic review. Lancet Neurol 5, 64-74.

57. Roriz-Filho JS, Sa-Roriz TM, Rosset I, et al. (2009) (Pre)diabetes, brain aging, and cognition. Biochim Biophys Acta 1792, 432-443

58. Hak AE, Pols HA, Stehouwer CD, et al. (2001) Markers of inflammation and cellular adhesion molecules in relation to insulin resistance in nondiabetic elderly: the Rotterdam study. I Clin Endocrinol Metab 86, 4398-4405.

59. Hull M, Strauss S, Berger M, et al. (1996) The participation of interleukin-6, a stress-inducible cytokine, in the pathogenesis of Alzheimer's disease. Behav Brain Res 78, 37-41.

60. Sorensen LB, Raben A, Stender S, et al. (2005) Effect of sucrose on inflammatory markers in overweight humans. $\mathrm{Am} \mathrm{J}$ Clin Nutr 82, 421-427.

61. Lee ZS, Chan JC, Yeung VT, et al. (1999) Plasma insulin, growth hormone, cortisol, and central obesity among young Chinese type 2 diabetic patients. Diabetes Care 22, 1450-1457.

62. Lupien S, Lecours AR, Lussier I, et al. (1994) Basal cortisol levels and cognitive deficits in human aging. J Neurosci 14, 2893-2903.

63. Akisaki T, Sakurai T, Takata T, et al. (2006) Cognitive dysfunction associates with white matter hyperintensities and subcortical atrophy on magnetic resonance imaging of the elderly diabetes mellitus Japanese elderly diabetes intervention trial (J-EDIT). Diabetes Metab Res Rev 22, 376-384.

64. Lazarus R, Prettyman R \& Cherryman G (2005) White matter lesions on magnetic resonance imaging and their relationship with vascular risk factors in memory clinic attenders. Int $J$ Geriatr Psychiatry 20, 274-279.

65. den Heijer T, Vermeer SE, van Dijk EJ, et al. (2003) Type 2 diabetes and atrophy of medial temporal lobe structures on brain MRI. Diabetologia 46, 1604-1610.

66. Greenwood CE (2003) Dietary carbohydrate, glucose regulation, and cognitive performance in elderly persons. Nutr Rev 61, S68-S74 